a differential fee schedule for physicians practising in areas where the cost of living is soaring, like Calgary and Fort McMurray.

Lee says the AMA also wants the province to renew funding for continuing operations in the I4 existing and I5 planned primary care networks (\$70 million in the 2006-07 budget), as well as for the Physician Office System Program (POSP), a \$65.6-million initiative that covered up to $70 \%$ of costs associated with a physician's move to electronic patient records.

The take-up rate among Alberta doctors was about 60\%-70\%, Lee says. But if POSP isn't renewed, "a lot of people will just have to go back to paper files again," which will reduce physician efficiency and productivity. "Without more funding, there's a risk of [POSP] going down the tubes."

Given the shortage of physicians and the high workloads doctors now shoulder as a result of the boom, "burn out" rates will soar, Lee adds. "If you don't have a medical services infrastructure to take care of the number of people coming into a boom province, there are going to be strains and stresses on the system and then something, of course, has to give." Wayne Kondro, CMAJ

DOI:I0.1503/cmaj.06I044

\section{News @ at a glance}

Clinical trial registry: The World Health Organization has launched a campaign urging research institutions and pharmaceutical companies to voluntarily register 20 core elements of all clinical trials involving human beings. The data are intended for inclusion in the WHO's proposed International Clinical Trials Registry Platform and are "fundamental to ensuring transparency in medical research and fulfilling ethical responsibilities to patients and study participants," said WHO Assistant Director General, Dr. Timothy Evans.

JAMA tightens disclosure: Starting in January 2007, the Journal of the American Medical Association (JAMA) will tighten its financial conflict-of-interest policy, requiring authors to list all links in the acknowledgement section of manuscripts. "All authors are required to disclose all potential conflicts of interest, including specific financial interests and relationships and affiliations... relevant to the subject of their manuscript," stated a July I 2 editorial. In the same issue, JAMA ran a correction disclosing drug industry ties by the authors of a study on the use of antidepressants among pregnant women. A week later, $J A M A$ ran a correction to an article revealing similar financial ties by authors of a study linking severe migraines to heart attacks in women.

Infectious disease tracking: The United Nations Food and Agricultural Organization, the World Organization for Animal Health (OIE) and the World Health Organization launched a global early warning system for zoonotic diseases in late July in the hope that better tracking will yield more coordinated responses to outbreaks of BSE, SARS, avian influenza and other infectious diseases. The organizations will share information on a Web-based electronic platform called the Global Early Warning and Response System. "From an animal health point of view, controlling contagious animal diseases in their early stages is easier and less expensive for the international community. In cases of zoonoses, this system will enable control measures that can also benefit public health," said OIE Director General, Dr. Bernard Vallat.

Global skin cancer rates: Worldwide, up to 60 ooo people die annually from malignant melanomas and other forms of skin cancer, according to the World Health Organization's first attempt to quantify the global health impact of ex- cessive exposure to the sun. The report (www.who.int/uv) also attempts to quantify other harmful effects of radiation, like eye cataracts and pterygium.

Marijuana dispensaries: Cannabis dispensaries, such as compassion clubs, should feel comfortable doling out marijuana if a patient has a "confirmation of diagnosis" from a medical practitioner that he or she suffers from I of 25 specified conditions, including migraines and chronic pain, according to a "best practices" manual developed by 2 British Columbia compassion clubs. Guidelines for the Community-Based Distribution of Medical Cannabis in Canada (www.thecompassionclub.org/resources

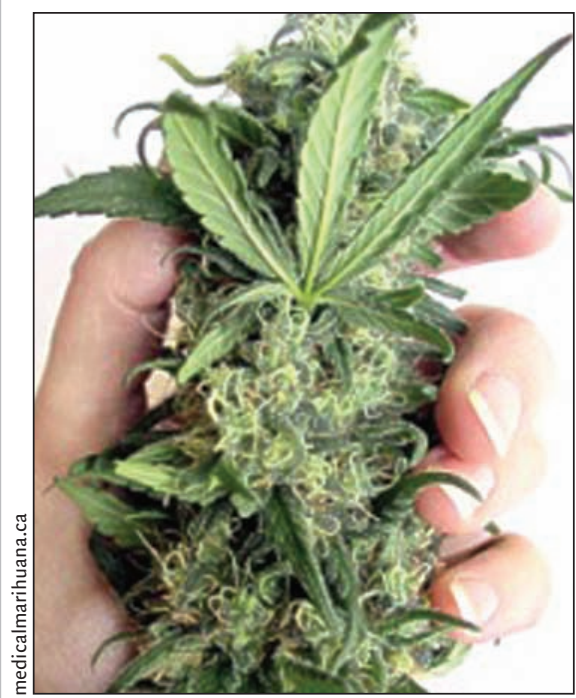

/guidelines.pdf) covers numerous marijuana distribution issues, including the need to counsel users on safe smoking techniques and to ensure that a variety of products are made available for users, including edible products that are wheat-, dairy- or sugar-free as well as "cannabisinfused cooking oil and butter." As it continues to be illegal to distribute marijuana, the document provides toll-free telephone numbers for legal aid services across the country. - Compiled by Wayne Kondro, CMAJ

DOI:I0.1503/cmaj.06I05I 